\title{
Relationships among Teachers' Knowledge and Beliefs Regarding the Teaching of Evolution: A Case for Turkey
}

\author{
Ceren Tekkaya • Gülsüm Akyol • Semra Sungur
}

Published online: 28 August 2012

(C) Springer Science+Business Media, LLC 2012

\begin{abstract}
The research study investigated the possible associations among science and biology teachers' knowledge and belief variables concerning teaching evolution in science and biology classes. Specifically, this study examined how a set of variables including teachers' understanding of evolution and nature of science (NOS) is related to the set of variables including teachers' acceptance of evolution and perceptions of teaching evolution (i.e., perceptions of the necessity of addressing evolution in their classrooms, perceptions of the factors that impede addressing evolution in their classrooms, and personal science teaching efficacy beliefs regarding evolution). Data were collected from science and biology teachers through administration of Evolution Content Knowledge Test, Measure of Acceptance of the Theory of Evolution, Nature of Science as Argument Questionnaire and Teachers' Perceptions of Teaching Evolution Scale. Canonical correlation analysis findings suggested that teachers who had thorough understanding of evolution and NOS were likely to both accept the scientific validity of evolution and believe the necessity of addressing evolution in the classrooms. On the other hand, teachers with thorough understanding of evolution and NOS did not necessarily believe that they have a stronger sense of self-efficacy beliefs regarding teaching evolution and that there are fewer obstacles to addressing evolution in the classroom. The research is significant in that it provides empirical evidence clarifying the interactions between teachers' understanding and beliefs in teaching evolution. Implications for science teacher education are discussed.
\end{abstract}

C. Tekkaya $\cdot$ G. Akyol $(\bowtie) \cdot$ S. Sungur

Faculty of Education, Department of Elementary Education, Middle East Technical University,

06800 Ankara, Turkey

e-mail: gakyol@metu.edu.tr

G. Akyol

Aksaray University,

Aksaray, Turkey
Keywords Evolution · Nature of science $\cdot$ Perception · Self-efficacy

\section{Introduction}

The significance of evolution to biological sciences has been recognized by major science and science education organizations including the American Association for the Advancement of Science (2006), National Academy of Sciences (1998), National Association of Biology Teachers (2008), and National Science Teachers Association (2003). As a central unifying theory, it serves as an explanation of similarities among organisms, biological diversity, and many characteristics of the physical world which are among the most basic characteristics of Earth (National Academy of Sciences 1998). Thus, evolution is an essential subject matter that provides individuals with understanding of life. However, the theory of evolution is not well understood by high school students (e.g., Kampourakis and Zogza 2008), undergraduate students (e.g., Alters and Nelson 2002; Peker et al. 2010), pre-service teachers (e.g., Akyol et al. 2010; Crawford et al. 2005; Deniz et al. 2008; Graf and Soran 2011), as well as in-service teachers (e.g., Nehm and Reilly 2007). Indeed, these findings are not surprising considering the extant research evidence that the theory of evolution has not been addressed effectively in science classes (e.g., Hermann 2008; Moore 2007; Moore and Kraemer 2005; Moore et al. 2006; Rutledge and Mitchell 2002; van Dijk 2009). For example, in an attempt to gain insights about the status of evolution instruction, a series of research studies were conducted in Minnesota by Moore and many of his colleagues (Moore 2007; Moore and Kraemer 2005; Moore et al. 2006). In the first study, Moore and Kraemer (2005) investigated high school biology teachers' views about teaching of evolution and creationism in the years 1995 
and 2003. The study reported an increase in percentages of teachers who addressed evolution as well as creationism in their classrooms. Data from the 2006 study, however, revealed the fact that even though mandated in the curriculum, evolution was not emphasized in high school biology course as intended. According to the 2007 study, Moore found a noteworthy difference in students' and teachers' perceptions about teaching evolution in biology courses; although most of the teachers stated that they gave emphasis to evolution in biology courses, relatively few students thought that their teachers emphasized or addressed evolution in biology courses. Along these lines, a Rutledge and Mitchell study (2002) demonstrated that as a central and unifying theme of biology, the theory of evolution was not reflected in the teaching of a relatively high number of Indiana public school biology teachers. It was reported that a third $(33 \%)$ of participating teachers devoted fewer than three days to teaching evolution whereas $43 \%$ of participants described their teaching of evolution as avoiding or briefly mentioning evolution in their instruction. As stressed earlier by Nelson, Nickels and Beard (1996), although evolution has an important place in modern science, teachers tend to overlook teaching this important topic due to fear of confrontation.

Related research dealing with effective evolution teaching identified a variety of obstacles that teachers confronted when teaching evolution. It was revealed that the problems of teaching evolution are generally philosophical, epistemological, and conceptual (Alters and Nelson 2002; Van Dijk and Reydon 2010; Smith 2010). More specifically, belief about nature of scientific knowledge and knowing (Rutledge and Mitchell 2002; Trani 2004), religious commitment (Aguillard 1999; Eve and Dunn 1990; Griffith and Brem 2004; Rutledge and Mitchell 2002; Trani 2004), worldviews (Cobern 1994), knowledge of evolution (Rutledge and Mitchell 2002; Trani 2004), belief regarding scientific validity of evolution (Aguillard 1999; BouJaoude et al. 2010; Eve and Dunn 1990; Rutledge and Warden 2000; Trani 2004), the pressure from parents and administrators (Moore and Kraemer 2005), ineffective pedagogy in evolution education and traditional ways of teaching evolution (Alters and Nelson 2002; Nelson 2007; Ingram and Nelson 2005; Scharmann 1994), college coursework in biology in general, evolution in particular (Aguillard 1999), anxiety level (Scharmann and Harris 1992), and stresses and coping strategies to alleviate the stresses (Griffith and Brem 2004), were reported to influence teachers' curricular and instructional decision while teaching evolution.

A recent study by Thagard and Findlay (2010), on the other hand, focuses especially on obstacles regarding accepting Darwin's theory. In their study, they summarized the main psychological obstacles to accepting Darwin's theory as cognitive obstacles (i.e., conceptual difficulties, methodological issues, and coherence problems that come from perception of alternative theories) and emotional obstacles (i.e., valued beliefs about God, souls, and morality). They pointed out that determining these obstacles may assist in promoting more efficient teaching strategies to deal with opposition to theory.

As far as belief about nature of scientific knowledge and knowing are considered, several research studies have indicated the importance of individuals' beliefs about nature of science (NOS) in teaching and learning science, including evolution. For example, according to Nelson (2007), a sound understanding of NOS is not only an important outcome on its own but also as a way of comprehending and resolving the debate over evolution. In line with this idea, Nelson suggested that NOS should be embedded into whole introductory biology topics rather than being taught as a separate topic restricted to just one chapter. Supporting Nelson's view, Cavallo and McCall (2008) proposed that students' misapprehension of scientific theories including evolutionary theory may be an outcome of their inadequate understanding of NOS. Additionally, according to Clough (1994), the debate between evolution and creation traces back to misconceptions about the NOS. Indeed, possessing a sound understanding of the NOS was reported to have a significant impact on individuals' understanding and acceptance of evolution (Akyol et al. 2010; Johnson and Peebles 1987; Kim and Nehm 2011; Lombrozo et al. 2008; Nelson 2007; Rutledge and Warden 2000; Scharmann and Harris 1991; Smith and Scharmann 1999). For example, in one of the studies, Cavallo and McCall (2008) found that students who believed in the tentative NOS were more likely to believe evolutionary theory compared to those viewing science as fixed and authoritative. They concluded that perceiving science as a dynamic process possibly makes students more receptive to controversial topics such as evolution. A number of studies indicated that individuals with thorough understanding of evolution and NOS are likely to believe that the theory of evolution is reliable since it is validated through accumulation of overwhelming evidence from varied methods; that like other scientific theories, evolutionary theory requires scientists' inference, imagination and creativity; and that are influenced by social factors, their personal beliefs and previous studies; and that like other scientific theories, evolutionary theory is subject to change as the result of new research and perspectives but does not develop into a law (see Lederman 2007; Lombrozo et al. 2008; McComas 2002; National Academy of Sciences 1998). As pointed out by Stears (2011), a sound understanding of NOS help students understand why evolution is considered to be the leading principle in biology as they develop consciousness about what a scientific theory means. It assists them in comprehension of what is regarded as evidence in science and accordingly adequacy of evidence for evolution, both in the past and now (Stears 2011). In line 
with Stears's ideas, it is reasonable to expect that teachers with a sound understanding of NOS feel more selfefficacious while teaching evolution, believing in their abilities to defuse controversy that may happen in their classroom. Czerniak and Haney (1998) reported that highly efficacious teachers are more likely to use open-ended inquiry, student-centered teaching strategies, tend to have less anxiety toward teaching science, and be more confident about teaching science while teachers with a low sense of efficacy are more likely to use teacher-directed teaching strategies such as lecture and reading from the textbook rather than hands-on instruction and spend less time developing science concepts. Moreover, it is also stressed that least efficacious preservice elementary teachers tend to be concerned about their own understanding of science. Indeed, Griffith and Brem (2004) stated that providing teachers with the latest information in evolution and genomics, a safe place to discuss the probable social and personal implications with other teachers, as well as with lesson plans integrated science with social and personal stories, lead them to feel more confident in teaching evolution. Thus, the literature mentioned above highlights that sound understanding of NOS and evolution has a central role in teachers' self-efficacy beliefs for teaching evolution. Researchers agree that teachers' science knowledge, attitudes and beliefs related to science and science teaching can have an influence on their classroom practices (e.g., Stepans and McCormack 1985; Stevens and Wenner 1996; Wenner 1993). Therefore, it can be said that for the sake of the quality of evolution instruction, it is important for science/biology teachers to accept the scientific validity of evolutionary theory, have sound understanding of both evolution and NOS, and have a stronger sense of self-efficacy beliefs regarding teaching evolution. Besides, Hokayem and BouJaoude (2008) stated that in order to understand students' and teachers' perceptions of the theory of evolution, it is vital to examine factors that may impact the growth of their perceptions.

By emphasizing the continued tension between belief, understanding, and acceptance of the theory of evolution, Hokayem and BouJaoude (2008) pointed up the crucial role that religious beliefs play in the way people view evolutionary theory (also see Downie and Barron 2000; Hermann 2008; Hokayem and BouJaoude 2008; Ingram and Nelson 2006; Lombrozo et al. 2008; Nadelson and Sinatra 2009; Nehm et al. 2009; Pennock 2007). According to the most recent study of BouJaoude et al. (2010), Lebanese teachers' conflicting views between evolution and religious beliefs and their knowledge of both evolution and pedagogical approaches had an influence on their instructional decisions regarding evolution. Likewise, in their study, Asghar, Wiles, and Alters (2007) identified Canadian preservice elementary teachers' concerns that they took into consideration for their instructional decisions about teaching evolution including type of school where they would work, inconsistent views between religion and evolution, inadequate understanding of evolution, and inadequate knowledge of related teaching techniques. In his correlational study, Trani (2004) found that Oregon biology teachers with strong understanding of both NOS and the theory of evolution accept evolution, albeit they are religious and had a tendency to translate this understanding to their practices. Moreover, Rutledge and Mitchell (2002) stated that Indiana public high school biology teachers' understanding of evolution and NOS and personal religious beliefs might contribute to both their acceptance and teaching of evolution. By using a clinical model of stress, Griffith and Brem (2004) identified the stresses experienced by a population of biology teachers in teaching evolution. The highest stress level was reported among the teachers who had a conflict between their religious beliefs and knowledge. The study of Nadelson and Sinatra (2009) found that acceptance significantly correlated with both knowledge of evolution and perceived evolution familiarity, that religiosity inversely correlated with acceptance of evolution, compatibility of beliefs and evolution, as well as with the knowledge. On the other hand, no statistically significant association was detected between religiosity and perception of familiarity with evolution. No relation was found between the number of courses and acceptance of evolution. Years of experience was reported to be significantly related to both acceptance of evolution and compatibility of faith and evolution. Their study also reported that although acceptance of evolution reported to be increased with years of experience, this variable failed to predict knowledge or religious commitment. Besides, years of academic experience, principal academic responsibility, level of education, number of college level biology courses, experience with researching and teaching science, and degree of religiosity, were statistically significantly related to the acceptance and/or the understanding of evolution. Thus, teachers endorsing strong anti-evolution views harbored some doubts about teaching evolution in a pedagogically responsible manner.

In the Rutledge and Mitchell study (2002) examining the relationship between public school teachers' acceptance of evolutionary theory and their academic backgrounds, a statistically significant association between teachers' acceptance of evolution and their exposure to courses related to biology, evolution, and NOS was found. In an attempt to update biology and earth science teachers' knowledge in NOS and knowledge of biological and geological science content related to evolutionary theory, Scharmann and Harris (1991) conducted a three-week summer institute. The study produced a significant increase in understanding and acceptance of evolutionary theory, understanding of NOS, as well as diminished participants' self-perceived 
anxiety level regarding teaching evolution in secondary science classes. Similarly, Nehm and Schonfeld (2007), although detecting a statistically significant improvement in biology teachers' knowledge on both evolution and NOS at the end of a 14-week intervention, found no change regarding their antievolutionary beliefs; many still preferred to teach antievolutionary ideas in their classes.

Although there is a growing body of literature on teaching evolution, it is clearly necessary to gain insight about teaching the related issue in a country like Turkey where evolution is part of both the science and biology curriculum. As well, a majority of Turkey's population is thought to be Muslim and there is a debate over evolution and creationism (see Deniz et al. 2008; Peker et al. 2010; Sayin and Kence 1999). Accordingly, this study aimed at examining science and biology teachers' perceptions of teaching evolution; specifically, their perceptions of the necessity of addressing evolution in their classrooms, perceptions of the factors that impede addressing evolution in their classrooms and their personal science teaching efficacy beliefs regarding evolution. With this approach, we may gain insights about the status of evolution instruction from teachers' perspective in an attempt to improve its quality. In addition, the finding that the theory of evolution is not taught effectively in the classrooms motivates us to unravel the possible factors that influence teachers' curricular and instructional decisions. In addition, to develop a better understanding of the relationship between knowledge and belief, described as one of the "significant core challenges for evolution education" by Nehm and Schonfeld (2007) and to uncover the inconsistent findings regarding the relationships among understanding, acceptance, and belief in evolution, as suggested by Smith (2010), the current study explores how a set of variables including science and biology teachers' understanding of evolution, and understanding of NOS is related to the set of variables including teachers' acceptance of evolution and perceptions of teaching evolution (i.e., perceptions of the necessity of addressing evolution in their classrooms, perceptions of the factors that impede addressing evolution in their classrooms, and personal science teaching efficacy beliefs regarding evolution). Studying the science and biology teachers who are responsible for teaching evolution in elementary and high schools is essential to reveal current status of evolution teaching. According to Butler (2009), success or failure of evolution education depends on science (biology) teachers who function at the border of the complex scientific and social factors that influence their classrooms. Therefore, there is a need to examine teachers' understanding and acceptance of evolution and their perceptions about teaching evolution in an attempt to improve evolution teaching.

\section{Contextual Background of the Study}

In Turkey, a majority of the population is thought to be Muslim, and there is a debate over evolution and creationism (see Deniz et al. 2008; Peker et al. 2010; Sayin and Kence 1999). In fact, according to the study of Miller et al. (2006) on public acceptance of evolution in the U.S., Japan, and 32 European countries, less than $30 \%$ of participating Turkish adults accepted the concept of evolution-the lowest proportion of acceptance of evolution among these countries. In a similar vein, studying with 1,098 freshman and senior undergraduate students enrolled in biology, biology education, and elementary science education, Peker et al. (2010) revealed that although $27.9 \%$ of the participants accepted the theory of evolution, $20.7 \%$ rejected it, and $51.4 \%$ were undecided about whether evolution occurred.

On the other hand, Turkey, has a centralized education system under the supervision of the Ministry of National Education, except for higher education (see Cakiroglu and Cakiroglu 2003; Deniz et al. 2008; Peker et al. 2010). Due to this centralized education system, elementary and high schools are required to follow the national curriculum associated with subject area suggested by the Ministry of National Education. Evolution is addressed in different ways in the national science and biology curriculum. As far as elementary science curriculum (grades 6-8) goes, evolution is presented in grade 8 as a part of the unit of "Cell Division and Inheritance" under the topic of "Adaptation and Evolution." Four objectives are named: namely, students are expected to (a) explain adaptation of living things to their environment by giving examples; (b) explain why different organisms living in the same habitat develop similar adaptation; (c) explain how adaptation contributes to biological diversity and evolution by giving examples; and finally, (d) give examples to different views about evolution (Ministry of National Education 2006). Although evolution is not discussed explicitly, some related concepts are also covered in the curriculum. For example, while fossils are addressed in the unit of "Earth and Universe" in grade 6, biological diversity is mentioned as a part of the unit of "Human Being and Environment" in grade 7. Besides, other related and important concepts such as mitosis, genetics, meiosis, and DNA and genetic code are presented in grade 8 . As far as the recently revised national biology curriculum (grades 9-12) is examined, it is noted that the curriculum guideline states that the evolution is to be studied longitudinally in conjunction with the other study contents (Ministry of National Education 2009). More specifically, units of the "Classification of living things and Biological Diversity," "Cell Division and Reproduction," "Heredity, Genetic Engineering and Biotechnology," and "Origin of the Life and Evolution" are addressed across the grade levels (grades 9-12). However, there is a specific 
chapter on evolution in grade 12, entitled "Origin of the Life and Evolution." The objectives are stated as: students are expected to (a) explain hypotheses and views pertaining to emergence of life such as abiogenesis, biogenesis, panspermia, autotroph, heterotroph, creation, and so on; (b) explain how fossils contribute to our understanding of life by giving examples; (c) explain how similarities and differences in organisms' embryological, biochemical, anatomical, and genetic structure contribute to the explanation of evolution by giving examples; (d) explain views related to evolution; and (e) discuss how the process of evolution and life can be affected by the environmental changes through time (Ministry of National Education 2009).

\section{Method}

\section{Participants}

Convenience sampling was used in the selection of the individuals rather than schools. Ninety-nine teachers $(73.7 \%$ female, 26.3\% male), who worked in elementary and high schools located in different regions of Turkey from different socio-economic levels, voluntarily participated in the study. Of 99 teachers, 76 were science teachers and 23 were biology teachers. In terms of teaching experience, about half of the participants' (43.9\%) experience ranged from two to five years whereas $26.5 \%, 17.3 \%$, and $12.2 \%$ of the participants had experience ranged from six to ten years, more than ten years, and one year, respectively. Participants were also requested to self-evaluate their level of both interest and knowledge about evolution. Of the participants, 59.2\% rated themselves as having "a little" interest in evolution and $20.4 \%$ rated as having "a great deal" of interest in evolution while few $(3.1 \%)$ claimed not to have interest in evolution. Besides, half of the participants reported having "sufficient" knowledge concerning evolution and $43.9 \%$ reported knowing "a little" concerning evolution whereas only $6.1 \%$ reported having "a lot" of knowledge concerning evolution.

\section{Measures}

In the present study, four instruments were used to collect data; (1) Evolution Content Knowledge Test, (2) Measure of Acceptance of the Theory of Evolution (MATE), (3) Nature of Science as Argument Questionnaire (NSAAQ) and (4) Teachers' Perceptions of Teaching Evolution Scale (TPTES).

\section{Evolution Content Knowledge Test}

Rutledge and Warden (2000) used a modified version of an existing scale (Johnson 1985) to assess teachers' understanding of theory of evolution. The test included 21 items with one correct answer and four distracters and covered the content areas; natural selection, extinction processes, homologous structures, coevolution, analogous structures, convergent evolution, intermediate forms, adaptive radiation, speciation, evolutionary rates, fossil record, biogeography, environmental change, genetic variability, and reproductive success. The test was translated and adapted into Turkish by Deniz et al. (2008). In the present study, two of the items in the Evolution Content Knowledge Test which did not contribute to total variability well and reduced internal consistency were removed. In these two items, participants were asked to identify the most compelling evidence for macroevolution and give an explanation for the rapid evolution once animal life invaded land from the oceans. The internal consistency of the resulting test was found to be .71 using Cronbach's alpha.

\section{Measure of Acceptance of the Theory of Evolution}

Rutledge and Warden (1999) originally developed the MATE to assess high school biology teachers' acceptance of evolutionary theory in terms of process of evolution, scientific validity of evolutionary theory, evolution of humans, evidence of evolution, scientific community's view of evolution, and age of the Earth. The MATE consists of 20 items (10 positively phrased and 10 negatively phrased items) on a five-point Likert scale ranging from 1 (strongly disagree) to 5 (strongly agree). In order to compute the overall MATE score, the negative items were reversed so that higher scores reflected higher levels of acceptance of evolutionary theory. The MATE was translated and adapted into Turkish by Tekkaya et al. (2010) and examined by a group of experts in science education. In order to validate the factor structure of the MATE for the present study, exploratory factor analysis (EFA) was conducted. Based on the EFA results, two items with low loadings were eliminated. These items were about the age of Earth. The remaining 18 items supported unidimensional factor structure assessing participants' "acceptance of the theory of evolution." The internal consistency of the MATE including 18 items was found to be .94 using Cronbach's alpha.

The Nature of Science as Argument Questionnaire

The NSAAQ was developed by Sampson and Clark (2006) to assess epistemological beliefs about nature of scientific knowledge, methods used to generate scientific knowledge, what counts as reliable and valid scientific knowledge and roles of scientists in the generation of scientific knowledge. The NSAAQ consists of 26 contrasting alternatives items which are divided into four subscales about nature of scientific knowledge (six items): methods that can be used to generate scientific knowledge (six items), what counts as reliable and valid scientific knowledge (seven items), and 
what role scientists play in the generation of scientific knowledge (seven items). Sampson and Clark (2006) computed total scores to reveal participants' views of the NOS without focusing on subscale scores. Higher scores indicated more sophisticated views on NOS: In the NSAAQ, two contrasting viewpoints for each item (one of the viewpoints indicates a more naïve epistemological beliefs about NOS, the other indicates consistency with the view of science as a process of explanation and argument) are given by using a five-point scale. The negative items were reversed so that higher scores reflected more consistenly the view of science as a process of explanation and argument. The NSAAQ was translated and adapted into Turkish by Tekkaya et al. (2010) and examined by a group of experts in science education. In order to validate the factor structure of the NSAAQ for the present study, EFA was conducted. The factor analysis suggested elimination of ten items to support unidimensonal factor structure. The remaining 16 items were used to assess participants' "understanding of the nature of science." In the present study, the internal consistency of NSAAQ including 16 items, was found to be .85 using Cronbach's alpha.

\section{Teachers' Perceptions of Teaching Evolution Scale}

Teachers' perceptions of teaching evolution were assessed by the Teachers' Perceptions of Teaching Evolution Scale. This scale was prepared by adapting items which were used by Lee et al. (2006), Pedretti et al. (2006), and Riggs and Enochs (1990). Overall, the modified questionnaire included 19 Likert-type items in three domains: teachers' perceptions of the necessity of addressing evolution in their classrooms, teachers' perceptions of the factors that impede addressing evolution in their classrooms, and personal science teaching efficacy beliefs regarding evolution. In order to validate the factor structure of the TPTES for the present study, EFA was conducted. The factor analysis suggested elimination of one item, and the remaining 18 items were aggregated under three target factors: "teachers' perceptions of the necessity of addressing evolution in their classrooms" (seven items), "teachers' perceptions of the factors that impede addressing evolution in their classrooms" (six items), and "personal science teaching efficacy beliefs regarding evolution" (five items). In the current study, the internal consistency of three domains of TPTES: "perceptions of the necessity of addressing evolution in their classrooms," "perceptions of the factors that impede addressing evolution in their classrooms," and "personal science teaching efficacy beliefs regarding evolution," including seven, six, and five items, respectively, were found to be $.84, .63$, and .68 , respectively, using Cronbach's alpha. The reliability coefficients for "perceptions of the factors that impede addressing evolution in their classrooms" and "personal science teaching efficacy beliefs regarding evolution" were somewhat low; however, it is not uncommon to have low Cronbach's alpha coefficient value for scales including less than ten items (Pallant 2007).

\section{Result}

\section{Descriptive Statistics}

The descriptive results regarding teachers' understanding of evolution, acceptance of evolution, understanding of NOS, perceptions of the necessity of introducing evolution into curriculum, perceptions of the factors that impede addressing evolution in their classrooms, and their personal science teaching efficacy for teaching evolution were reported in the following sections. For the presentation of the data, the "strongly agree" and "agree" responses were combined to give the proportions of teachers who affirmed the statements and the "strongly disagree" and "disagree" responses were combined to give the proportions of teachers who dissented with the statements.

\section{Teachers' Understanding of Evolution}

Of 19 possible correct responses on the evolution content knowledge test, a mean score of $9.40(\mathrm{SD}=3.29)$ was attained by the participants. That is, participants responded correctly to about $50 \%$ of the questions, indicating a moderate level of understanding of evolution (see Table 1). For example, even if more than one third $(38.4 \%)$ of the participants gave a correct response to an item about the evolutionary theory proposed by Charles Darwin by selecting "change in populations through time as a response to

Table 1 The frequency distributions of teachers' correct responses to items of evolution content knowledge test (in percentage)

\begin{tabular}{lll}
\hline $\begin{array}{l}\text { Item } \\
\text { Number }\end{array}$ & Item topic & $\begin{array}{l}\text { Correct } \\
\text { response }\end{array}$ \\
\hline 1 & $\begin{array}{l}\text { Evolutionary theory proposed by Charles } \\
\text { Darwin }\end{array}$ & 38.4 \\
2 & Homologous structure & 38.4 \\
4 & Process of evolution & 25.3 \\
10 & Role of genetic variability in natural selection & 34.3 \\
11 & Darwin's theory of natural selection & 51.5 \\
14 & Darwin's theory of natural selection & 44.4 \\
16 & Mechanisms contributing to genetic variability & 90.9 \\
17 & $\quad$ within a species & 57.6 \\
18 & Txample of intermediate form & 32.3 \\
19 & The earliest fossils found in the geologic & 19.2 \\
20 & Radiometric dating principles & 62.6 \\
\hline
\end{tabular}


environmental change" option, approximately the same number of participants $(35.4 \%)$ chose "change in populations through time as a result of mutations" option. Concerning question about homologous structure, 38.4\% of the participants stated correctly that the wing of the bat and the forelimb of the dog are similar structures due to common ancestry, while $27.3 \%$ acknowledged that they have a different ancestry but a common function. In another item, the process of evolution was correctly described by about one quarter $(25.3 \%)$ as "change of populations through time." Many participants, however, defined the process of evolution as "the change of simple to complex organisms" $(41.3 \%)$ and as "the development of characteristics in response to need" (18.2\%). In one of the items, participants were asked to identify the option that best represents Lamarck's ideas on the evolutionary process. Although more than half of the participants $(62.6 \%)$ believed that inheritance of acquired characteristics represents Lamarck's ideas on the evolutionary process best, one third (33.3\%) thought that it is the survival of the fittest that represents Lamarck's ideas.

In another item, the reason for why Darwin's theory of natural selection did not fully explain how evolution could occur when first proposed was asked. Less than half (44.4\%) gave a correct response to this question by selecting "the fact that accurate mechanisms explaining genetic inheritance were not widely known" option, whereas $25.3 \%$ identified the reason as the absence of biochemical techniques to determine the genetic similarities between species. As clearly seen from Table 1, although participants of our study seemed to be knowledgeable about the role of meiosis in generating individual variability, they had difficulty in understanding radiometric dating techniques.

\section{Teachers' Acceptance of Evolution}

Turkish teachers could be described as average with regard to their acceptance of evolution. The scores for this sample ranged from 1.28 to 5.00 , and the average score was 3.48 $(\mathrm{SD}=.85)$. As evident in Table 2, regarding process of evolution, a majority of the participants thought that "organisms existing today are the result of evolutionary processes that have occurred over millions of years" (75.7\%) and "the theory of evolution brings meaning to the diverse characteristics and behaviors observed in living forms" (71.4\%). Also, 78.4\% indicated that they did not think "organisms exist today in essentially the same form in which they always have." Concerning human evolution, although over $58 \%$ expressed their agreement on the idea that "modern humans are the product of evolutionary processes that have occurred over millions of years," a considerable proportion

Table 2 The frequency distributions of teachers' responses to the MATE instrument

\begin{tabular}{|c|c|c|c|c|c|}
\hline \multirow[b]{2}{*}{ Items } & \multicolumn{5}{|c|}{ Percentages } \\
\hline & SA & A & $\mathrm{U}$ & $\mathrm{D}$ & SD \\
\hline $\begin{array}{l}\text { 1. Organisms existing today are the result of evolutionary processes that have occurred over millions of } \\
\text { years }\end{array}$ & 44.4 & 31.3 & 3 & 13.1 & 8.1 \\
\hline 2. The theory of evolution is incapable of being scientifically tested & 6.1 & 13.3 & 30.6 & 30.6 & 19.4 \\
\hline 3. Modern humans are the product of evolutionary processes that have occurred over millions of years & 28.6 & 29.6 & 7.1 & 20.4 & 14.3 \\
\hline 4. The theory of evolution is based on speculation and not valid scientific observation and testing & 13.1 & 20.2 & 16.2 & 37.4 & 13.1 \\
\hline 5. Most scientists accept evolutionary theory to be a scientifically valid theory & 14.3 & 45.9 & 21.4 & 14.3 & 4.1 \\
\hline 6. The available data are ambiguous (unclear) as to whether evolution actually occurs & 14.3 & 29.6 & 16.3 & 27.6 & 12.2 \\
\hline 8. There is a significant body of data that supports evolutionary theory & 17.5 & 43.3 & 16.5 & 13.4 & 9.3 \\
\hline 9. Organisms exist today in essentially the same form in which they always have & 6.2 & 9.3 & 6.2 & 42.3 & 36.1 \\
\hline 10. Evolution is not a scientifically valid theory & 7.1 & 12.2 & 18.4 & 37.8 & 24.5 \\
\hline 12. Current evolutionary theory is the result of sound scientific research and methodology & 13.4 & 45.4 & 17.5 & 17.5 & 6.2 \\
\hline 13. Evolutionary theory generates testable predictions with respect to the characteristics of life & 11.1 & 41.4 & 22.2 & 22.2 & 3 \\
\hline 14. The theory of evolution cannot be correct since it disagrees with the creation & 10.4 & 11.5 & 21.9 & 30.2 & 26 \\
\hline 15. Humans exist today in essentially the same form in which they always have & 12.2 & 11.2 & 4.1 & 37.8 & 34.7 \\
\hline 16. Evolutionary theory is supported by factual historical and laboratory data & 25.3 & 40.4 & 14.1 & 12.1 & 8.1 \\
\hline 17. Much of the scientific community doubts if evolution occurs & 12.4 & 28.9 & 26.8 & 24.7 & 7.2 \\
\hline $\begin{array}{l}\text { 18. The theory of evolution brings meaning to the diverse characteristics and behaviors observed in living } \\
\text { forms }\end{array}$ & 20.4 & 51 & 11.2 & 9.2 & 8.2 \\
\hline 19. With few exceptions, organisms on earth came into existence at about the same time & 5.2 & 12.5 & 19.8 & 32.3 & 30.2 \\
\hline 20. Evolution is a scientifically valid theory & 21.2 & 39.4 & 17.2 & 13.1 & 9.1 \\
\hline
\end{tabular}

$S A$ strongly agree, $A$ agree, $U$ undecided, $D$ disagree, $S D$ strongly disagree 
of the participants $(34.7 \%)$ disagreed with this statement. Regarding the scientific validity of evolutionary theory, over half of the participants agreed with items such as "current evolutionary theory is the result of sound scientific research and methodology" (58.8\%) and "evolutionary theory generates testable predictions with respect to the characteristics of life" (55.5\%). Regarding the scientific community's view of evolution, $60.2 \%$ of the participants thought that "most scientists accept evolutionary theory to be a scientifically valid theory"; however, only $31.9 \%$ disagreed that "much of the scientific community doubts if evolution occurs." As far as undecided items are concerned, participants expressed a considerable level of uncertainty about items such as "the theory of evolution is incapable of being scientifically tested" (30.6\%); "much of the scientific community doubts if evolution occurs" (26.8\%); "evolutionary theory generates testable predictions with respect to the characteristics of life" (22.2\%); "the theory of evolution cannot be correct since it disagrees with the creation" $(21.9 \%)$; "most scientists accept evolutionary theory to be a scientifically valid theory" (21.4\%).

\section{Teachers' Understanding of Nature of Science}

Participants' responses to the NSAAQ also demonstrated a moderate level of understanding of NOS $(M=3.43$, $\mathrm{SD}=.74)$. The scores for this sample ranged from 1.25 to 4.88. As given in Table 3, regarding the nature of scientific knowledge, while a majority of the participants $(83.5 \%)$ thought that scientific knowledge usually changes over time as the result of new research and perspectives, only $25.3 \%$ thought that scientific knowledge is subjective. Concerning items about methods used to generate scientific knowledge, $53.6 \%$ of the participants agreed that "science is best described as a process of exploration and experiment." However, a considerable proportion of participants $(31.3 \%)$ was undecided about this idea. Related to reliability and validity of scientific knowledge, less than half of the participants thought that the reliability and trustworthiness of data should always be questioned (44.4\%) and that scientists know that atoms exist because they have made observations that can only be explained by the existence of such particles $(35.4 \%)$. On the other hand, concerning reliability and validity of scientific knowledge, participants expressed their agreement on items indicating more naïve ideas such as "a theory should be considered inaccurate if a single fact exists that contradicts that theory" $(23.5 \%)$; "the scientific method can provide absolute proof" $(20.2 \%)$; and "when a scientific investigation is done correctly errors and biases are eliminated" $(20.2 \%)$. Besides, less than half of the participants agreed with the items found in scientists' role in the generation of scientific knowledge category such as "in order to interpret the data they gather scientists rely on their prior knowledge, logic, and creativity" (43.9\%); "the observations made by two different scientists about the same phenomenon can be different" (39.4\%); "scientists are

Table 3 The frequency distributions of teachers' responses to the NSAAQ

\begin{tabular}{|c|c|c|c|c|c|c|}
\hline \multirow{2}{*}{$\begin{array}{l}\text { Item } \\
\text { Viewpoint A }\end{array}$} & \multicolumn{5}{|c|}{ Percentages } & \multirow{2}{*}{$\begin{array}{l}\text { Item } \\
\text { Viewpoint B }\end{array}$} \\
\hline & A not B & $\begin{array}{l}A> \\
B\end{array}$ & $\begin{array}{l}A= \\
B\end{array}$ & $\begin{array}{l}B> \\
A\end{array}$ & $B \operatorname{not} A$ & \\
\hline 3. Scientific knowledge is subjective & 25.3 & 6.1 & 10.1 & 14.1 & 44.4 & Scientific knowledge is objective \\
\hline $\begin{array}{l}\text { 4. Scientific knowledge does not change over } \\
\text { time once it has been discovered }\end{array}$ & 5.1 & 0 & 0 & 11.1 & 83.8 & $\begin{array}{l}\text { Scientific knowledge usually changes over time as } \\
\text { the result of new research and perspectives }\end{array}$ \\
\hline $\begin{array}{l}\text { 14. The scientific method can provide } \\
\text { absolute proof }\end{array}$ & 20.2 & 22.2 & 9.1 & 27.3 & 21.2 & $\begin{array}{l}\text { It is impossible to gather enough evidence to } \\
\text { prove something true }\end{array}$ \\
\hline $\begin{array}{l}\text { 15. If data was gathered during an } \\
\text { experiment } \\
\text { it can be considered reliable andtrustworthy }\end{array}$ & 6.1 & 9.1 & 11.1 & 29.3 & 44.4 & $\begin{array}{l}\text { The reliability and trustworthiness of data should } \\
\text { always be questioned }\end{array}$ \\
\hline $\begin{array}{l}\text { 18. A theory should be considered inaccurate } \\
\text { if a single fact exists that contradicts that } \\
\text { theory }\end{array}$ & 23.5 & 30.6 & 9.2 & 19.4 & 17.3 & $\begin{array}{l}\text { A theory can still be useful even if one or more } \\
\text { facts contradict that theory }\end{array}$ \\
\hline $\begin{array}{l}\text { 20. In order to interpret the data they gather } \\
\text { scientists rely on their prior knowledge, } \\
\text { logic, and creativity }\end{array}$ & 43.9 & 29.6 & 8.2 & 5.1 & 13.3 & $\begin{array}{l}\text { In order to interpret the data they have gather } \\
\text { scientists rely on logic only and avoid using their } \\
\text { creativity or prior knowledge }\end{array}$ \\
\hline $\begin{array}{l}\text { 23. Two scientists (with the same expertise) } \\
\text { reviewing the same data will reach the } \\
\text { same conclusions }\end{array}$ & 20.4 & 24.5 & 24.5 & 13.3 & 17.3 & $\begin{array}{l}\text { Two scientists (with the same expertise) reviewing } \\
\text { the same data will often reach different } \\
\text { conclusions }\end{array}$ \\
\hline $\begin{array}{l}\text { 25. The observations made by two different } \\
\text { scientists about the same phenomenon will } \\
\text { be the same }\end{array}$ & 12.1 & 8.1 & 8.1 & 32.3 & 39.4 & $\begin{array}{l}\text { The observations made by two different scientists } \\
\text { about the same phenomenon can be different }\end{array}$ \\
\hline
\end{tabular}


influenced by social factors, their personal beliefs, and past research" (27.3\%); and "two scientists (with the same expertise) reviewing the same data will often reach different conclusions" (17.3\%).

Teachers' Perceptions of the Necessity of Addressing Evolution in Their Classrooms

Participants' perceptions about the necessity of addressing evolution in their classrooms were evaluated by seven items in TPTES. Results revealed that Turkish teachers had a high degree of agreement on the necessity of addressing evolution in their classrooms $(M=4.05, \mathrm{SD}=.71)$. The scores for this sample ranged from 1.14 to 5.00; higher scores reflected higher levels of perceptions of the necessity of addressing evolution in their classrooms. More specifically, as evident in Table 4, a majority of the participants viewed teaching evolution as important as teaching the rest of the science topics $(81.8 \%)$ and believed that teaching evolution was worth the effort and time (87.9\%). In addition, participating teachers acknowledged the necessity of addressing the inadequacy of students' background regarding evolution $(91.9 \%)$ and expressed their willingness to use materials in class related to evolution if they can get them $(79.8 \%)$, to develop teaching and learning materials on evolution $(75.8 \%)$, and to participate in a program that helps teachers deal with evolution (74.5\%). On the other hand, while relatively fewer participants $(59.6 \%)$ agreed that introducing evolution into science classes would increase students' interest in science, a considerable proportion of the participants was undecided about this item (26.3\%).

Teachers' Perceptions of the Factors that Impede Addressing Evolution in Their Classrooms

Turkish teachers' perceptions of the factors that impede addressing evolution in their classrooms were assessed by six items in TPTES. Participants' responses uncovered several obstacles to addressing evolution in their classrooms $(M=2.73, \mathrm{SD}=.70)$. The scores for this sample ranged from 1.00 to 4.50 ; higher scores reflected more obstacles to addressing evolution in their classrooms. Thus, the descriptive findings suggested that participants had some difficulties in addressing evolution in their classrooms. More specifically, as shown in Table 5, a considerable proportion of participants agreed that addressing evolution in science classes could confuse students about their own values (57.6\%), students are not mature enough to be interested in and understand evolution (42.5\%), and science classes addressing evolution have little influence on the achievement of students with low motivation (or low-level of participation; 38.4\%). Furthermore, participants indicated a relatively high level of uncertainty about items including "dealing with evolution using various teaching strategies (role playing and group activities) is hardly possible in a 'real' classroom situation" (25.3\%), "classes dealing with evolution are most likely to be classes for high achieving students" (24.2\%), and "I believe that science classes addressing evolutionary theory have little influence on the achievement of students with low motivation (or low-level of participation)" (22.2\%).

\section{Teachers' Personal Science Teaching Efficacy Beliefs regarding Evolution}

Participants' personal science teaching efficacy beliefs regarding evolution was evaluated by five items in TPTES. As can be in Table 6, Turkish teachers had a moderate sense of self-efficacy beliefs regarding teaching evolution $(M=3.51$, $\mathrm{SD}=.66)$. In fact, they seemed not to be highly confident in their abilities to teach evolution. The scores for this sample ranged from 1.80 to 5.00; higher scores reflected higher levels of personal science teaching efficacy beliefs regarding evolution. Frequency analyses revealed that a majority of the participants seemed to perceive themselves as having sufficient understanding of evolution (79.4\%). Relatively

Table 4 The frequency distributions of teachers' responses regarding their perceptions of the necessity of addressing evolution in their classrooms

\begin{tabular}{|c|c|c|c|c|c|}
\hline \multirow[t]{2}{*}{ Item } & \multicolumn{5}{|c|}{ Percentages } \\
\hline & SA & A & $\mathrm{U}$ & $\mathrm{D}$ & SD \\
\hline 1. I want to develop teaching and learning materials on evolution for my science/biology class & 36.4 & 39.4 & 9.1 & 14.1 & 1 \\
\hline 2. If I can get materials on evolution, I am willing to use them in class & 21.2 & 58.6 & 13.1 & 5.1 & 2 \\
\hline 3. I am willing to participate in a program that helps teachers deal with evolution & 41.8 & 32.7 & 16.3 & 7.1 & 2 \\
\hline 4. The inadequacy of students' background regarding evolution needs to be addressed & 48.5 & 43.4 & 6.1 & 1 & 1 \\
\hline 5. Introducing evolution into science/biology classes will increase students' interest in science & 25.3 & 34.3 & 26.3 & 9.1 & 5.1 \\
\hline 6. Evolution education is not as important as the rest of the science/biology curriculum & 4 & 7.1 & 7.1 & 38.4 & 43.4 \\
\hline 7. Teaching evolution is not worth the effort and time & 5.1 & 3 & 4 & 32.3 & 55.6 \\
\hline
\end{tabular}

$S A$ strongly agree, $A$ agree, $U$ undecided, $D$ disagree, $S D$ strongly disagree 
Table 5 The frequency distributions of teachers' responses regarding perceptions of the factors that impede addressing evolution in their classrooms

\begin{tabular}{|c|c|c|c|c|c|}
\hline \multirow[t]{2}{*}{ Item } & \multicolumn{5}{|c|}{ Percentages $(\%)$} \\
\hline & SA & A & $\mathrm{U}$ & $\mathrm{D}$ & SD \\
\hline 2. I believe that students are not mature enough to be interested in and understand evolution & 15.2 & 27.3 & 12.1 & 35.4 & 10.1 \\
\hline 3. I believe that students are barely interested in evolution & 7.1 & 8.1 & 9.1 & 42.4 & 33.3 \\
\hline 4. Classes dealing with evolution are most likely to be classes for high achieving students & 2 & 12.1 & 24.2 & 35.4 & 26.3 \\
\hline $\begin{array}{l}\text { 5. I believe that science/biology classes addressing evolution have little influence on the achievement of } \\
\text { students with low motivation (or low level of participation) }\end{array}$ & 8.1 & 30.3 & 22.2 & 30.3 & 9.1 \\
\hline 6. Addressing evolution in science/biology classes could confuse students about their own values & 15.2 & 42.4 & 12.1 & 23.2 & 7.1 \\
\hline $\begin{array}{l}\text { 7. Dealing with evolution using various teaching strategies (role plays and group activities) is hardly } \\
\text { possible in a "real" classroom situation }\end{array}$ & 10.1 & 13.1 & 25.3 & 35.4 & 16.2 \\
\hline
\end{tabular}

$S A$ strongly agree, $A$ agree, $U$ undecided, $D$ disagree, $S D$ strongly disagree

fewer participants seemed to be confident about their knowledge necessary to teach evolution to their students effectively $(62.6 \%)$ and their abilities to use various teaching strategies to deal with evolution in science classes (61.2\%). In addition, participants expressed a relatively high level of uncertainty related to their abilities to develop teaching and learning materials about evolution (35.4\%) and their knowledge necessary to teach evolution to their students $(27.3 \%)$. Furthermore, $22 \%$ were not sure about their ability to teach evolution as well as they did most subjects, even if they tried hard.

\section{Teachers' Acceptance of Evolution and Perceptions}

of Teaching Evolution in relation to Their Understanding of Evolution and Nature of Science

Canonical correlation analysis was conducted to investigate relationships between a set of variables including teachers' understanding of evolution and NOS and another set of variables including teachers' acceptance of evolution, perceptions of the necessity of addressing evolution in their classrooms, perceptions of the factors that impede addressing evolution in their classrooms, and their personal science teaching efficacy beliefs for teaching evolution. The aim of canonical correlation is to analyze the relationships between two set of variables. In the present study, the variables in each set were determined considering the related literature: Because the related literature suggested that understanding of evolution and NOS is related to acceptance of evolution and perceptions regarding teaching evolution, one of the sets in the analysis included understanding variables and other set included acceptance and perception variables.

Canonical correlation analysis revealed that the first canonical correlation was .36 (13.08\% overlapping variance). With all two canonical correlations included, $\chi^{2}(8)=14.51$, $p=.069$. The first pair of canonical variates did not account for the significant relationships between the two sets of variables, yet the percentage of variance values revealed that the first canonical variate pair extracts considerable proportion of variance from set $1(56 \%)$ and set 2 variables $(25 \%)$. Therefore, it was used as a base for interpreting the relationship between a set of variables including teachers' understanding of evolution and NOS and another set of variables including teachers' acceptance of evolution, perceptions of the necessity of addressing evolution in their classrooms, perceptions of the factors that impede addressing evolution in their classrooms, and their personal science teaching efficacy beliefs for teaching evolution. The

Table 6 The frequency distributions of teachers' responses regarding personal teaching efficacy about evolution

\begin{tabular}{|c|c|c|c|c|c|}
\hline & \multicolumn{5}{|c|}{ Percentages } \\
\hline & SA & A & $\mathrm{U}$ & $\mathrm{D}$ & SD \\
\hline 1. Even when I try very hard, I do not teach evolution as well as I do most subjects & 6.1 & 25.3 & 22.2 & 34.3 & 12.1 \\
\hline 2. I am able to use various teaching strategies to deal with evolution in science/biology classes & 15.3 & 45.9 & 17.3 & 18.4 & 3.1 \\
\hline 3. I sufficiently understand what evolution is & 18.6 & 60.8 & 8.2 & 12.4 & 0 \\
\hline 4. I have confidence in developing teaching and learning materials about evolution & 11.1 & 34.3 & 35.4 & 15.2 & 4 \\
\hline 5. I have the knowledge necessary to effectively teach about evolution to my students & 12.1 & 50.5 & 27.3 & 9.1 & 1 \\
\hline
\end{tabular}

$S A$ strongly agree, $A$ agree, $U$ undecided, $D$ disagree, $S D$ strongly disagree 
nonsignificant finding, despite a considerable proportion of variance values, can be due to small sample size. Hence, the generalization of the present findings should be viewed with caution. We recommended replicating the present research study with more participants.

As shown in Table 7, with a cutoff correlation of .3 (Tabachnick and Fidell 2007), all the variables in set 1 were correlated with the first canonical variate. Among variables in set 2, acceptance of evolution and perceptions of the necessity of addressing evolution in the classrooms were found to be correlated with the first canonical variate. The first pair of canonical variates indicated that understanding of evolution (.70) and understanding of NOS (.79) were associated with acceptance of evolution (.90) and perceptions of the necessity of addressing evolution in the classrooms (.30).

This finding implied that teachers who have thorough understanding of evolution and NOS are likely to accept the scientific validity of evolution and perceive the necessity of addressing evolution in their classrooms.

On the other hand, understanding of both evolution and NOS was not correlated with any of variables including perceptions of the factors that impede addressing evolution in the classrooms and personal science teaching efficacy beliefs regarding evolution.

Besides, the percentage of variance values revealed that the first canonical variate pair extracts $56 \%$ of variance of the variance from set 1 variables and $25 \%$ of the variance from set 2 variables. Redundancy values indicated that the "acceptance of evolution, perceptions of the necessity of addressing evolution in the classrooms, perceptions of the factors that impede addressing evolution in the classrooms, and self-efficacy beliefs about teaching of evolution" variate accounts for $7.3 \%$ of the variance in the "understanding of evolution and nature of science." Likewise, the "understanding of evolution and nature of science" variate accounts for $3.2 \%$ of the variance in the "acceptance of evolution, perceptions of the necessity of addressing evolution in the classrooms, perceptions of the factors that impede addressing evolution in the classrooms, and self-efficacy beliefs about teaching evolution" variables (Table 7).

\section{Discussion}

Evolution, as a central and unifying theme of the biological science (Rutledge and Mitchell 2002), is one of the required topic presented in the Turkish science and biology curriculum. An understanding of contemporary views of evolution, is therefore considered an important outcome of school science in Turkey. Consequently, science and biology teachers need to understand evolution if they are to help students develop views consistent with those accepted by the
Table 7 Correlations, standardized canonical coefficients, canonical correlations, percents of variance, and redundancies between variables in set 1 and variables in set 2 and their corresponding canonical variates

scientific community. It is obvious that teachers cannot possibly teach what they do not understand and believe-in this case, evolution. Thus, to increase quality in evolution education, teachers should be adequately prepared to teach evolution with confidence and possess accurate conceptions. Yet, the findings of the current study are not promising; Turkish teachers, similar to their counterparts in other nations, are found to be struggling with certain difficulties both in grasping the process of evolution and in accepting the scientific validity of the theory of evolution. Turkish science teachers in general do not perceive themselves highly confident in their ability to teach evolution effectively and express some doubts in their ability to function in some important aspects of teaching evolution, such as understanding concepts well enough to be effective in teaching evolution. Some participants feel that their confidence in teaching evolution is low compared to other subjects found in the curriculum and some are not sure whether they teach evolution as well as they do other subjects even if they try very hard. There could be several reasons for this perception. For example, they may be thinking that they don't understand evolution as well as other topics presented in the curriculum or because they are reacting to the controversial nature of this topic. However, qualitative research depending on indepth interviews and classroom observations is the most appropriate strategy for determining underlying reasons. Although studies emphasize the importance of adopting sound pedagogical practices when teaching evolution (Alters and Nelson 2002), our teachers seemed to harbor some doubt about their pedagogical content knowledge (PCK) necessary to teach evolution effectively in their science/biology classrooms. The results of the evolution 
concept test also confirmed their inadequate understanding of evolution (see Table 1). For example, the majority of teachers found it difficult to appreciate that radiometric dating techniques rely on the fact that the Earth contains elements which change into other elements at a constant known rate, that the process of evolution is a change of populations through time; that using radioactive dating techniques, the first life seems to have appeared on the earth about 3.3 billion years ago; and that the evolutionary theory proposed by Charles Darwin was change in populations through time as a response to environmental change. On the other hand, it is a highly promising finding that teachers reported the necessity to address evolution in the classroom. Indeed, participants' belief in the need of addressing evolution in the classroom is quite high $(M=4.05)$. For example, they indicated their willingness to develop and use teaching and learning materials on evolution as well as participate in a program aimed to help teachers dealt with this topic. Further, they perceived evolution education as important as other topics found in the curriculum and worth effort and time. However, they were relatively undecided whether introducing evolution increases their students' interest (see Table 4).

As deduced from Turkish science and biology teachers' responses to scale related to perceptions about the factors that impede addressing evolution in their classrooms, "addressing evolution in science/biology classes could confuse students about their own values" emerged as the most important factor hindering their evolution instruction. Participants, however, appeared to be undecided on whether items including "classes dealing with evolution are most likely to be classes for high achieving students," "I believe that science/biology classes addressing evolution have little influence on the achievement of students with low motivation (or low-level of participation)," and "dealing with evolution using various teaching strategies (role playing and group activities) is hardly possible in a 'real' classroom situation" impede their instruction. Of course, the factors reported as impeders that hamper teaching evolution were limited to ones found in the self-report instrument. Thus, further studies are needed to reveal all potential factors by using qualitative data collection procedures such as interviews.

In addition, as understood from the their responses to MATE, Turkish science and biology teachers appeared to harbor some doubts about the scientific validity of evolution and the scientific community's view of evolution: they are not sure whether the theory of evolution generates testable predictions with respect to the characteristics of life and it is correct since it disagrees with creationism and/or whether scientific community is in agreement if evolution occurs and accept it to be a scientifically valid theory. Their uncertainty was highest in the item reflecting scientific validity of evolution: "The theory of evolution is incapable of being scientifically tested." Therefore, participants appeared to have a struggle in accepting scientific validity of theory of evolution.

Present data led to the conclusion that sound understanding of evolution and NOS is related to teachers' acceptance of scientific validity of evolution and their perceptions concerning the necessity of addressing evolution in their classes. However, such understanding makes no practical contribution to their perceived ability to teach evolution effectively. Moreover, teachers' understanding of evolution and NOS is not found to be linked to their perceptions of the factors that impede addressing evolution in Turkish science/ biology classrooms.

Firstly, we found that sound understanding of evolution and NOS was related to perceptions of the necessity of addressing evolution in the science classrooms. This finding is contrast to the finding by Nehm and Schonfeld (2007), which suggested that although it may be necessary for science teachers to have knowledge of evolution and NOS, it is not sufficient to impact their preference about teaching evolution. However, supporting the present finding, Rutledge and Warden (2000) stated that teachers' lack of knowledge about evolutionary theory and NOS are among potential drawbacks to stressing evolution in the high school biology curriculum. In addition, Maldonado-Rivera (1998) found that although evolution was placed in the official state science curriculum, teaching of evolution was disregarded by teachers. The author added that teacher's inadequate knowledge of NOS and the structure of biological knowledge were significant factors influencing the effectiveness of teaching of evolutionary theory. Moreover, Rutledge and Mitchell (2002) and Rutledge and Warden (2000) pointed out the importance of teachers' understanding of evolutionary theory and NOS to make plausible instructional and curricular decisions with regard to teaching evolution. Definitely, for the current study, teachers with sound understanding of evolution and NOS tend to believe the necessity of introducing evolution into existing curriculum.

Our findings also indicate that understanding of evolution and NOS was associated with teachers' acceptance of scientific validity of evolution. In fact, parallel to the current finding, several studies in the literature resulted in positive relationships between understanding and acceptance of evolution (e.g., Deniz et al. 2008; Rutledge and Warden 2000) and between understanding of NOS and acceptance of evolution (e.g., Akyol et al. 2010; Kim and Nehm 2011; Lombrozo et al. 2008; Rutledge and Warden 2000). Based on these relationships, it can be concluded that acceptance of evolution is linked to understanding of both evolution and NOS. Indeed, it seems that understanding of NOS and understanding of evolution may support each other, which in turn may promote acceptance of evolution as pointed out by Lombrozo et al. (2008). 
As stated previously, the current study indicated that teachers' understanding of evolution and NOS is correlated with each of the variables including their acceptance of evolution and perceptions of the necessity of addressing evolution in the classrooms. Accordingly, it is reasonable to expect that teachers' acceptance of evolution is also related to their perceptions of the necessity of addressing evolution in the classrooms. In other words, it can be said that teachers' acceptance of evolution is likely to facilitate addressing the issue of evolution in their instruction. Parallel with this idea, BouJaoude et al. (2010) confirmed that teachers' acceptance and rejection of evolution obviously had an influence on their instructional decisions. In detail, according to teachers who did not accept or selectively accepted evolutionary theory, (a) evolutionary theory ought not to be taught, (b) time spent for evolution and creationism ought to be the same, or (c) evolutionary theory ought to be taught so that students can speak their mind concerning the theory. Besides, the time spent for evolution instruction was found to be related to teacher's level of acceptance of evolutionary theory in research by Rutledge (1996) and Aguillard (1999). That is, teacher's high level of acceptance of evolutionary theory gave rise to increase in spent time for evolution instruction. At this point, it should be noted that in spite of the association between teachers' acceptance of evolution and perceptions of the necessity of addressing evolution in the classrooms, participating teachers of the present study demonstrated a moderate level of acceptance of evolution. Actually, this is an expected finding considering descriptive results indicating that teachers had moderate level understanding of evolution and NOS.

On the other hand, the present data revealed no evidence that understanding of both evolution and NOS is correlated with perceptions of the factors that impede addressing evolution in classrooms. That is, teachers with thorough understanding of evolution and NOS did not necessarily believe that there are fewer obstacles to addressing evolution in their classrooms. This finding is not surprising considering the items used in the domain of "perceptions of the factors that impede addressing evolution in their classrooms." Indeed, the items did not directly refer to factors related to understanding of evolution and NOS. More specifically, they reflected factors involving difficulties in employment of various teaching strategies (e.g., role playing and group activities). The items also denoted perceptions of whether students were able to or mature enough to deal with evolution and whether addressing evolution in science/biology classes could confuse students about their own values. It should be remembered that factors reported as impeders of addressing evolution in the classrooms were assessed through items found in the self-report instrument. We perceived this as a limitation of the study and recommended using qualitative data collection procedures such as interviews to uncover all possible factors.
Furthermore, the current study failed to indicate significant associations between understanding of both evolution and NOS and personal science teaching efficacy beliefs concerning evolution. That is, teachers with thorough understanding of evolution and NOS did not necessarily believe in their knowledge and abilities to teach evolution effectively. When items in the domain of "Teachers' Personal Science Teaching Efficacy Beliefs regarding Evolution" were taken into consideration, it appeared that items reflected perceptions of whether teachers were confident about their knowledge to deal with evolution and whether they were able to use various teaching strategies as well as to develop teaching and learning materials regarding evolution. Therefore, considering the items, it can be said that although it may be necessary to have sound understanding of evolution and NOS, it is not adequate to have an influence on self-efficacy beliefs regarding teaching evolution. Providing a partial support for the current finding, Abd-El-Khalick and Lederman (2000) suggested that adequate understanding of NOS is necessary but not sufficient for translation of this knowledge into practice. On the other hand, several other researchers reported a positive and significant relationship between science knowledge and self-efficacy beliefs (Nadelson and Nadelson 2000; Sarikaya et al. 2005; Tekkaya et al. 2004). More specifically, studying perceptions and preparedness of K-8 educators about teaching evolution, Nadelson and Nadelson (2000) found that K-8 educators' perceived familiarity with concepts of evolutionary theory was positively related with their perceived qualifications about teaching evolutionary theory. In addition, according to a Tekkaya et al. (2004) study, there was a positive and significant relationship between preservice science teachers' science knowledge and self-efficacy beliefs. Moreover, in the study of Sarikaya and others (2005), preservice elementary teachers' science knowledge level was found to make a significant contribution to their personal science teaching efficacy beliefs. Besides, Stears (2011) pointed out that teachers with an enhanced understanding of NOS feel more self-efficacious while teaching evolution, believing in their abilities to defuse controversy which may arise in their classroom. Certainly, it is obvious that there is not enough research to interpret impacts of teachers' understanding of evolution and NOS on their teaching efficacy beliefs regarding evolution. Hence, there should be more research to draw conclusions about related issue.

The present findings clearly indicate that teachers with thorough understanding of evolution and NOS are likely to accept the scientific validity of evolution as well as believe the necessity of addressing evolution in the classrooms. Accordingly, considering the importance of teachers' acceptance of evolution and belief in the need of addressing evolution in the classroom for the quality of evolution 
education, it is vital for teachers to have thorough understanding of not only the theory of evolution, but also features of a scientific theory and how a scientific theory is generated. Unfortunately, participating teachers demonstrate moderate levels of understanding of evolution and NOS. Therefore, there is an urgent need to develop teachers' knowledge based on evolution as well as on NOS. This can be achieved, for example, by designing effective inservice training programs. Indeed, a series of study conducted by a group of Turkish researchers (Cakiroglu et al. 2009; Dogan et al. 2011) provided evidence for the effectiveness of an in-service program involving explicit reflective NOS instruction on the development of science teachers' NOS understanding. Accordingly, similar programs can also be conducted by teachers involving content-embedded explicit reflective NOS instruction focusing specifically on evolution. Several empirical research projects have demonstrated the effectiveness of explicit reflective context-based NOS instruction in improving both pre- and in-service teachers' NOS views (e.g., Matkins and Bell 2007; Wahbeh 2009). On the other hand, the study by Schwartz and Lederman (2002), in which two beginning teachers having different level of NOS understanding, science background knowledge, and experience were used as a case study, provided evidence that understanding of NOS, subject matter knowledge as well as perceived link between science subject matter and NOS influenced not only teaching but also learning NOS. They also found that the participant having a great deal of science background and possessing informed views about NOS was better capable of addressing NOS during his teaching. In another study, Lederman (1999) conducted a multiple case study with five high school biology teachers with differing teaching experience to explore the association between teachers' NOS understanding and their classroom practice. He concluded that teachers' conceptions of science do not necessarily have an effect on their classroom practice. The significance of teachers' experience, intentions, and students' perceptions were also highlighted.

Considering the important role that teacher education programs play in training qualified teachers, we suggest that teacher education programs should be designed to promote sound understanding of both evolution and NOS. As far as teacher education programs are concerned, for example, AbdEl-Khalick (2005) examined the effect of a philosophy of science course on preservice teachers' NOS views, perceptions of teaching about NOS, and instructional planning related to NOS. His study tentatively showed that participating in a philosophy of science course helps teacher candidates develop deeper, more coherent NOS understanding and enables them to translate this understanding into explicitly planned instructional sequences. He suggested developing integrated courses organized around critical episodes in the history of science that focus on the needs of science teachers. He stated that case studies of these episodes, like the shift from a geocentric to a heliocentric model of the solar system and the development of evolutionary theory, could be utilized in order to acquaint science teachers with some fundamental issues in philosophy and sociology of science and a complete understanding of science works and generation of some fundamental scientific theories (see also Abd-El-Khalick and Lederman 2000 for review). The research by Scharmann et al. (2005) with preservice secondary science teachers concluded that comprehension of NOS conceptions is improved when those conceptions are presented through explicit reflective NOS instruction. In addition, Butler's (2009) study with college students supported the assertion that explicit and reflective NOS instruction plays a crucial role in the learning and teaching of biological evolution. The study by Akerson et al. (2000) provided further support for the effectiveness of a reflective, explicit, activity-based NOS instruction on preservice teachers' NOS views. They, however, claimed that such instruction combined with a conceptual change approach might become more efficient. Similarly, Clough (2006), approved the importance of explicit reflective NOS instruction, he emphasized the necessity of conceptual change for effective NOS instruction. What is more, in order to develop student understanding and abilities regarding evolution and NOS activities incorporating a five-step instructional model including engagement, exploration, explanation, elaboration, and evaluation were suggested in "Teaching About Evolution and the Nature of Science" (National Academy of Science 1998).

The present study has a number of limitations which might have implications for further research studies. First, canonical correlation analysis, despite a considerable proportion of variance values, did not result in a significant relationship between a set of variables including teachers' understanding of evolution and NOS and another set of variables including teachers' acceptance of evolution, perceptions of the necessity of addressing evolution in their classrooms, perceptions of the factors that impede addressing evolution in their classrooms, and their personal science teaching efficacy beliefs for teaching evolution. This can be due to small sample size. Besides, since there were only 99 science and biology teachers participating in the study, the results may not be reliable if generalized to Turkey's population as a whole. It is possible that the teachers who were more or less supportive of the theory of evolution voluntarily participated in the study. Thus, the generalization of the present findings should be viewed with caution. We recommended replicating the present research study with more participants. Second, this study was conducted with science and biology teachers without focusing on the differences in their responses to the self-report instruments. Future studies with a larger sample size can examine whether science and biology teachers differ concerning their understanding of evolution, acceptance of evolution, understanding of NOS and 
perceptions of teaching evolution. Third, participants' acceptance of evolution, understanding of NOS and perceptions about teaching of evolution were measured on the basis of self-reports. However, self-reported instruments may not capture participants' actual thoughts, so it is desirable for further study to make greater use of multiple methods and measures to verify the consistency and accuracy of the self-reported data. Fourth, items of evolution content knowledge test evaluating understanding of evolution were limited to 19 multiple choice questions. Thus, future studies can develop and use more comprehensive tests or use different assessment techniques including diagnostic tests, concept maps, and interviews to uncover understanding of evolution. Fifth, factors reported in the TPTES were limited to ones found in the scale. Hence, further studies can uncover all possible factors related to teachers' perceptions of teaching evolution by using qualitative data collection procedures such as interviews. Sixth, the internal consistency of two domains of TPTES; "perceptions of the factors that impede addressing evolution in their classrooms" and "personal science teaching efficacy beliefs regarding evolution" were found to be .63 and .68, respectively, using Cronbach's alpha. Although these reliability coefficients were somewhat low, it is not uncommon to have low Cronbach's alpha coefficient value for scales including less than ten items (Pallant 2007). In this situation, Pallant suggested reporting mean inter-item correlation for the items. The mean inter-item correlations for the items of "perceptions of the factors that impede addressing evolution in their classrooms" and "personal science teaching efficacy beliefs regarding evolution" were .22 and .31 , respectively, that are in the optimal range for the inter-item correlation of .2 and .4 as suggested by Briggs and Cheek (1986, as cited in Pallant 2007). Hence, in future studies, additional items can be prepared and included in these subscales to improve the reliability of the findings. Last, while generalizations are not possible due to the correlational and exploratory nature of the study, the results suggest that further study of teachers' ideas about evolution is warranted.

Despite these limitations, we feel that this study extends our understanding of possible associations among teachers' knowledge and belief variables concerning teaching evolution in science and biology classes. To concude: the present findings suggest that sound understanding of both evolution and NOS may have a crucial impact on beliefs in evolution and in the need to introduce evolution into the curriculum. We hope that this investigation will serve as a motivating force for further research in the area of evolution education.

\section{References}

Abd-El-Khalick F, Lederman NG. The influence of history of science courses on students' views of nature of science. J Res Sci Teach. 2000;37(10):1057-95.
Abd-El-Khalick F. Developing deeper understandings of nature of science: the impact of a philosophy of science course on preservice science teachers' views and instructional planning. Int J Sci Educ. 2005; 27:15-42.

Aguillard D. Evolution education in Louisiana public schools: a decade following Edwards v. Aguillard. Am Biol Teach. 1999;61:182-8.

Akerson VL, Abd-El-Khalick F, Lederman NG. Influence of a reflective explicit activity-based approach on elementary teachers' conceptions of nature of science. J Res Sci Teach. 2000;37:295-317.

Akyol G, Sungur S, Tekkaya C. The contribution of understandings of evolutionary theory and nature of science to pre-service science teachers acceptance of evolutionary theory. Procedia Soc Behav Sci. 2010;9:1889-93.

Alters BJ, Nelson C. Perspective: teaching evolution in higher education. Int J Org Evo. 2002;56:1891-901.

American Association for the Advancement of Science (AAAS). Statement on the teaching of evolution. In: Web site of AAAS. 2006. http:// www.aaas.org/news/releases/2006/pdf/0219boardstatement.pdf. Accessed 12 Dec 2011.

Asghar A, Wiles JR, Alters B. Canadian preservice elementary teachers' conceptions of biological evolution and evolution education. McGill J Educ. 2007;42(2):189-209.

BouJaoude S, Asghar A, Wiles JR, Jaber L, Sarieddine D, Alters B. Biology professors'and teachers' positions regarding biological evolution and evolution education in a Middle Eastern society. Int J Sci Educ. 2010. doi:10.1080/09500693.2010.489124.

Briggs SR, Cheek JM. The role of factor analysis in the development and evaluation of personality scales. Journal of Personality. 1986;54:106-48

Butler W. Does the nature of science influence college students' learning of biological evolution? (Unpublished Doctoral Dissertation). Florida State University, Florida; 2009.

Cakiroglu E, Cakiroglu J. Reflections on teacher education in Turkey. Eur J Teach Educ. 2003;26(2):253-64.

Cakiroglu J, Dogan N, Bilican K, Cavus S, Arslan O. Influence of inservice teacher education program on science teachers' views of nature of science. Int J Learn. 2009;16(10):597-606.

Cavallo AML, McCall D. Seeing may not mean believing: examining students' understandings and beliefs in evolution. Am Biol Teach. 2008;70(9):522-30.

Clough MP. Diminish students' resistance to biological evolution. Am Biol Teach. 1994;56:409-15.

Clough MP. Learners' reponses to the demands of conceptual change: considerations for effective nature of science instruction. Sci \& Educ. 2006;15(4):465-94.

Cobern WW. Point: Belief, understanding, and the teaching of evolution. J Res Sci Teach. 1994;31:583-90.

Crawford BA, Zembal-Saul C, Munford D, Friedrichsen P. Confronting perspective teachers' ideas of evolution and scientific inquiry using technology and inquiry-based tasks. J Res Sci Teach. 2005;42:613-37.

Czerniak C, Haney J. The effect of collaborative concept mapping on elementary preservice teachers' anxiety, efficacy, and achievement in physical science. J Sci Teach Educ. 1998;9:303-20.

Deniz H, Donnelly LA, Yilmaz I. Exploring the factors related to acceptance of evolutionary theory among Turkish preservice biology teachers: toward a more informative conceptual ecology for biological evolution. J Res Sci Teach. 2008;45(4):420-43.

Dogan N, Cakiroglu J, Cavus S, Bilican K, Arslan O. Developing science teachers' nature of science views: the effect of in-service teacher education program. Hacettepe University J Educ. 2011;40:127-39.

Downie JR, Barron NJ. Evolution and religion: attitudes of Scottish first year biology and medical students to the teaching of evolutionary biology. J Biol Educ. 2000;34(3):139-47.

Eve RA, Dunn D. Psychic powers, astrology, and creationism in the classroom? Evidence of pseudoscientific beliefs among high 
school biology life science teachers. The Am Biol Teach. 1990;52 (1): 10-21.

Graf D, Soran H. Evolutionstheorie-Akzeptanz und Vermittlung im europäischen Vergleich. Einstellung und Wissen von Lehramtstudierenden zur Evolution-ein Vergleich zwischen Deutschland und der Türkei. In: Graf D, editor. Tagungsband Einstellung und Wissen zu Evolution und Wissenschaft in Europa. Heidelberg: Springer; 2011. p. 141-61.

Griffith JA, Brem SK. Teaching evolutionary biology: pressures, stress, and coping. J Res Sci Teach. 2004;41(8):791-809.

Hermann RS. Evolution as a controversial issue: a review of instructional approaches. Sci Educ. 2008;17:1011-32.

Hokayem H, BouJaoude S. College students' perceptions of the theory of evolution. J Res Sci Teach. 2008;45(4):395-419.

Ingram EL, Nelson CE. Relationship between achievement and students' acceptance of evolution or creation in an upper-level evolution course. J Res Sci Teach. 2005;43(1):7-24.

Ingram EL, Nelson CE. Relationship between achievement and students' acceptance of evolution or creation in an upper-division evolution course. J Res Sci Teach. 2006;43:7-24.

Johnson RL. The acceptance of evolutionary theory by biology majors in colleges of the west north central states (Unpublished Doctoral Dissertation). University of Northern Colorado, Greeley; 1985.

Johnson RL, Peebles EE. The role of scientific understanding in college: student acceptance of evolution. Am Biol Teach. 1987;49:93-8.

Kampourakis K, Zogza V. Students' intuitive explanations of the causes of homologies and adaptations. Sci Educ. 2008;17(1):27-47.

Kim SY, Nehm RH. A cross-cultural comparison of Korean and American science teachers' views of evolution and the nature of science. Int J Sci Educ. 2011;33(2):197-227.

Lederman NG. Teachers' understanding of the nature of science and classroom practice: factors that facilitate or impede the relationship. J Res Sci Teach. 1999;36(8):916-29.

Lederman NG. Nature of science: past, present, and future. In: Abell SK, Lederman NG, editors. Handbook of research in science education. Englewood Cliffs, NJ: Erlbaum; 2007. p. 831-79.

Lee H, Abd-El-Khalick F, Choi K. Korean science teachers' perceptions of the introduction of socio-scientific issues into the science curriculum. Can J Sci Math Technol Educ. 2006;6(2):97-118.

Lombrozo T, Thanukos A, Weisberg M. The importance of understanding the nature of science for accepting evolution. Evo Edu Outreach. 2008;1(1):290-8.

Maldonado-Rivera JG. An examination of the factors affecting the teaching and learning of evolution (Unpublished Doctoral Dissertation). Columbia University, New York; 1998.

Matkins JJ, Bell RL. Awakening the scientist inside: global climate change and the nature of science in an elementary science methods course. J Sci Teach Educ. 2007;18:137-63.

McComas WF. The principle elements of the nature of science: dispelling the myths. In: McComas WF, editor. The nature of science in science education: rationales and strategies. New York: Kluwer; 2002. p. 53-70.

Miller JD, Scott EC, Okamato S. Science communication: public acceptance of evolution. Science. 2006;313:765-6.

Ministry of National Education of Turkey. Science and technology curriculum of elementary schools (6th-8th grades) [in Turkish]. Ankara, Turkey: Board of Education; 2006.

Ministry of National Education of Turkey. Biology curriculum of secondary schools (9th-12th grades) [in Turkish]. Ankara, Turkey: Board of Education; 2009.

Moore R. The differing perceptions of teachers and students regarding teachers' emphasis on evolution in high school biology classrooms. Am Biol Teach. 2007;69(5):268-71.

Moore R, Kraemer K. The teaching of evolution and creationism in Minnesota. Am Biol Teach. 2005;67:457-66.
Moore R, Froehle A, Kiernan J, Greenwald B. How biology students in Minnesota view evolution, the teaching of evolution and the evolution-creationism controversy. Am Biol Teach. 2006;68 (5):35-42.

Nadelson LS, Nadelson S. K-8 educators perceptions and preparedness for teaching evolution topics. J Sci Teach Educ. 2000. doi:10.1007/s10972-009-9171-6.

Nadelson LS, Sinatra GM. Educational professionals understanding and acceptance of evolution. J Evol Psychol. 2009;7(4):490-516.

National Academy of Sciences. Teaching about evolution and the nature of science. Washington, DC: National Academy Press; 1998.

National Association of Biology Teachers (NABT). NABT Statement on teaching evolution. 2008. In: Web site of NABT. http://www.nabt.org/ websites/institution/index.php?p=92. Accessed 12 Dec 2011.

National Science Teachers Association (NSTA). NSTA position statement: The teaching of evolution. In: Web site of NSTA. 2003. http:/ www.nsta.org/about/positions/evolution.aspx. Accessed 12 Dec 2011.

Nehm RH, Reilly L. Biology majors' knowledge and misconceptions of natural selection. Bioscience. 2007;57(3):263-72.

Nehm RH, Schonfeld IS. Does increasing biology teacher knowledge of evolution and the nature of science lead to greater preference for teaching of evolution in schools. J Sci Teach Educ. 2007; 18:699-723.

Nehm RH, Kim S, Sheppard K. Academic preparation in biology and advocacy for teaching evolution: biology versus non-biology teachers. Sci Educ. 2009;93(6):1122-46.

Nelson CE. Teaching evolution effectively: a central dilemma and alternative strategies. McGill J Educ. 2007;42(2):265-84.

Nickels MK, Nelson CE, Beard J. Better biology teaching by emphasizing evolution and the nature of science. The Am Biol Teach. 1996;58(6):332-6.

Pallant J. SPSS survival manual: a step by step guide to data analysis using SPSS for Windows. Maidenhead: Open University Press; 2007.

Pedretti E, Bencze L, Hewitt J, Romkey L, Jivraj A. Promoting issuesbased STSE perspectives in science teacher education: problems of identity and ideology. Sci Educ. 2006;17:941-60.

Peker D, Comert GG, Kence A. Three decades of anti-evolution campaign and its results: Turkish undergraduates' acceptance and understanding of the biological evolution theory. Sci Educ. 2010;19:739-55.

Pennock RT. Learning evolution and the nature of science using evolutionary computing and artificial life. McGill J Educ. 2007;42:211-24.

Riggs IM, Enochs LG. Toward the development of an elementary teacher's science teaching efficacy belief instrument. Sci Educ. 1990;74(6):625-37.

Rutledge ML. Indiana high school biology teachers and evolutionary theory: Acceptance and understanding (Unpublished Doctoral Dissertation). Ball State University, Indiana; 1996.

Rutledge ML, Mitchell MA. High school biology teachers' knowledge structure, acceptance, and teaching of evolution. Am Biol Teach. 2002;64(1):21-7.

Rutledge ML, Warden MA. The development and validation of the measure of acceptance of the theory of evolution instrument. School Science and Mathematics. 1999;99(1):13-8.

Rutledge ML, Warden MA. Evolutionary theory, the nature of science and high school biology teachers: critical relationships. Am Biol Teach. 2000;62(1):23-31.

Sampson V, Clark D. The development and validation of the Nature of Science as Argument Questionnaire (NSAAQ). In Annual Conference of the National Association of Research in Science Teaching (NARST), San Francisco, CA; 2006.

Sarikaya H, Cakiroglu J, Tekkaya C. Self-efficacy, attitude and science knowledge. Academic Exchange Q. 2005;9(4):38-42.

Sayın U, Kence A. Islamic scientific creationism: a new challenge in Turkey. Reports of the National Center for Science Education. 1999;19:18-29. 
Scharmann LC. Teaching evolution: designing successful instruction. J Sci Teach Educ. 1994;5(4):122-9.

Scharmann, LC, Harris WM. Teaching evolution: Understanding, concerns, and instructional approaches. In the Annual International Conference of the National Association of Research in Science Teaching (NARST), Lake Geneva, WI; 1991.

Scharmann LC, Harris WM. Teaching evolution: understanding and applying the nature of science. J Res Sci Teach. 1992;29(4):375-88.

Scharmann LC, Smith MU, James MC, Jensen M. Explicit reflective nature of science instruction: evolution, intelligent design, and umbrellaology. J Res Sci Teach. 2005;16:27-41.

Schwartz RS, Lederman NG. "It's the nature of the beast": the influence of knowledge and intentions on learning and teaching nature of science. J Res Sci Teach. 2002;39:205-36.

Smith MU. Current status of research in teaching and learning evolution: I. Philosophical/epistemological issues. Sci Educ. 2010;19:523-38.

Smith MU, Scharmann LC. Defining versus describing the nature of science: a pragmatic analysis for classroom teachers and science educators. Sci Educ. 1999;83:493-509.

Stears M. Exploring biology education students' responses to a course in evolution at a South African university: implications for their roles as future teachers. J Biol Educ. 2011. doi:10.1080/ 00219266.2011 .560171$.

Stepans J, McCormack A. A study of scientific conceptions and attitudes toward science of prospective elementary teachers: a research report. 1985; ERIC Document Reproduction Service No. ED 226024.
Stevens C, Wenner GJ. Elementary preservice teachers' knowledge and beliefs regarding science and mathematics. Sch Sci Math. 1996;96(1):2-9.

Tabachnick BG, Fidell LS. Using multivariate statistics. 5th ed. New York: Allyn and Bacon; 2007.

Tekkaya C, Cakiroglu J, Ozkan O. Turkish preservice science teachers' understanding of science, and their confidence in teaching science. J Educ Teach. 2004;30:57-66.

Tekkaya C, Akyol G, Sungur S. Evrim teorisini kabul etmeye etki eden faktörler: Evrim bilgisinin ve bilimsel bilginin doğasi ile ilgili görüşlerinin incelenmesi. Poster presented at the meeting of IX. Ulusal Fen Bilimleri ve Matematik Eğitimi Kongresi, İzmir, Turkey; 2010.

Thagard P, Findlay S. Getting to Darwin: obstacles to accepting evolution by natural selection. Sci Educ. 2010;19(6-8):625-36.

Trani R. I won't teach evolution, it's against my religion; And now for the rest of the story. The Am Biol Teach. 2004;66:419-42.

Van Dijk EM. Teachers' views on understanding evolutionary theory: a PCK study in the framework of the ERTE-model. Teach Teach Educ. 2009;25:259-67.

Van Dijk EM, Reydon TAC. A conceptual analysis of evolutionary theory for teacher education. Sci Educ. 2010;19(6-8):655-77.

Wahbeh NAK. The effect of a content-embedded explicit-reflective approach on in-service teachers' views and practices related to nature of science. University of Illinois, Urbana; 2009.

Wenner GJ. Relationship between science knowledge levels and beliefs toward science instruction held by pre-service elementary teachers. J Sci Educ Technol. 1993;2:461-8. 